\title{
Hermenéutica para un mundo que necesita auto-comprenderse: $W$. Dilthey y Heidegger
}

\author{
Beatriz Nájera ${ }^{1}$ \\ En este artículo se expone la noción de comprensión para introducir al lector \\ en los problemas y aportes de la hermenéutica filosófica en la configuración de \\ una nueva racionalidad.
}

This article introduces the reader to the problems and contributions of the philosophical hermeneutics in the configuration of a new rationality.

\section{Introducción.}

"Siempre existió ese aspecto único y universal de la civilización, pero solamente ahora tenemos una conciencia vívida de ello. Somos, sin duda, la primera época histórica que incluye como hecho dominante la conciencia de pertenecer a una única civilización global”².

Barbarie o civilización, civilización o barbarie. He ahí el dilema. Durante mucho tiempo se han usado dichas categorías para distinguir y separar a los diferentes grupos humanos. A un lado los barbaros, al otro los civilizados. En la cita anterior Ricoeur sigue otra ruta, la de concebirnos en la línea de ser que nos hace uno. Pero no siempre se ha usado y usa en esa dirección.

El término bárbaro asentó su uso en Europa, por parte de los grupos grecolatinos, para distinguir a las comunidades que hablaban otras lenguas y pertenecían a otra cultura. Durante la llustración fue asociada a cultura y se concibió la existencia de culturas superiores e inferiores. De modo que se generó una polaridad: cultura/civilización. De igual forma la palabra civilización (del latín -civis -ciudadano) surge para referirse a sociedades que desde sus cánones de comprensión eran entendidas como refinadas, en contraposición a las que ante sus ojos resultaban primitivas o bárbaras: "Esta palabra aparece por primera vez en la lengua francesa del siglo XVIII, y con ella se significaba la refinación de las costumbres. Civilización es un término relacionado con la idea de progreso. Según esto, la civilización es un estado de la humanidad, en el cual la ignorancia ha sido abatida y las costumbres y relaciones sociales se hallan en su más elevada expresión"3.

1. Directora del Departamento de Arte y Cultura, de la Universidad Don Bosco

2. RICOEUR, Paul.: Política, sociedad e historicidad, Ed. Docencia, Buenos Aires, 1986, P.19.

3. En. es.wikipedia.org/wiki/Cultura , consultada el $11 / 6 / 11$. 
La percepción era de índole cultural y poco a poco fue adquiriendo un matiz fuertemente cargado de una ideología de integración y superioridad étnica que decantó en una visión justificadora de la acción social, y pasó de su uso como distinción del ámbito social, al nacional, con el surgimiento de los nacionalismos del siglo XIX.

Así, las naciones industrializadas se identificaron con los términos y éstos siguieron el camino de la ideología, en tanto imaginario de las naciones que se entendían pertenecientes al grupo de los pueblos civilizados. Así, estas categorías en tanto ideología, activaron la función justificadora y legitimadora de la acción social y se utilizaron, paradójicamente, para la legitimación de "actos de vandalismo, saqueo, sangrías, sometimientos, asesinatos masivos, abuso y dominación de unos grupos por otros. Justamente los que así actuaban lo hicieron en diferentes momentos en nombre de los valores de la civilización y contra los bárbaros que amenazaban, con solo el hecho de existir, la estabilidad, intereses y estilo de vida del grupo civilizador. Pero tal conducta no es exclusiva de Occidente, ni de los países industrializados, ni de nuestra época. La observamos en todos los grupos humanos, y en diferentes momentos de la historia. Llámese incas, aztecas, japoneses, españoles, hunos, otomanos, islámicos, alemanes, mongoles, griegos, romanos, zulúes, hutus. Cada uno en su tiempo, "en su puntual ahora", y en su rodeo ha desatado debacles contra otros mundos, con la fe ciega de estar actuando en nombre de un valor superior.

Así se ha desatado la barbarie, tal como el término se ha llegado a comprender, en diferentes épocas y lugares. En su momento las acciones de masiva violencia siempre han tenido su legitimación: en nombre de Dios, la libertad, el emperador, la república, el capital, el partido, la justicia etc. Cada quien en lo suyo se ha justificado a su momento, frente al escenario de muerte y sufrimiento en que "nos" embarcamos y que "nos" infringimos unos a otros. Una condición compartida por toda la especie humana. Nos hermana la capacidad de ser caóticos, pero también de ser y de ser ordenados, racionales y además ser ordenados para el caos y caóticos para el orden.

Lo que resulta dramático es que nada hay que nos asegure que el horror no volverá, que la locura se disipará, y los genocidios, los ataques de unos contra otros no volverán a ocurrir. Este es más bien el suculento plato del cual nos alimentamos diariamente. De forma más o menos sutil, insinuada, o en su faz más descarada, el siglo XX ha sido un testamento claro, como el agua, de nuestro poder destructivo y sanador, civilizados y bárbaros, que habitan en nosotros, en cada uno, a nivel individual y como colectividades.

En su momento, toda barbarie ha tenido su razón y toda razón su barbarie. En los inicios de la modernidad, civilización se utilizó como una ideología(tomada este último término en su sentido peyorativo): “Originariamente, civilización avanzada, o simplemente civilización , es un concepto desarrollado a partir de un enfoque etnocentrista y valorativo, propio de los investigadores sociales europeos y americanos que, con el progreso de la investigación intercultural y 
el intento de analizar y comprender las culturas ajenas desde sus condiciones objetivas y específicas, ha perdido significado"4.

Por su parte, el término barbarie(en el sentido más bien actos intencionados de brutalidad desatada contra otros con el fin de someterlos) desde un reduccionismo biológico, podría interpretarse, tal accionar violento, como una funcionalidad latente que aflora de cuando en vez y de vez en cuando, como el animal que defiende su territorio, su manada. Desde otro enfoque más teológico, podría interpretar como el signo del pecado original. Un punto de vista psicológico lo vería como el deseo de poder, seguridad, control, inhibidos, que busca canales donde aflorar o encuentra condiciones de amenaza que activan su respuesta de defensa, un dominio, que se justifica desde la razón; la que es usada para justificar la salida de la bestia insaciable que llevamos dentro; a fin de que ésta pueda salir a dar un paseo cuando la avidez de sangre nos desborda.

El caso que nos interesa es que pareciera que estamos condenados a repetir una y otra vez nuestros errores. Catástrofes de la convivencia humana ante los cuales no hemos podido "inventar" una vacuna o un software, que nos libre de tales hecatombes. Ante estas repetidas catástrofes de la convivencia humana, resulta válido buscar respuestas enfocadas a la búsqueda de la comprensión en un mundo que cada vez nos pone cara a cara, inexorablemente, unos a otros, por los flujos migratorios, el libre comercio, las comunicaciones, en fin el movimiento de la globalización.

Como parte de la dinámica del universo, nos encontramos entre fuerzas opuestas que nos unen y separan. Por un lado, seguimos la dirección de un mundo único generado por el modelo económico y los desastres compartidos producto de nuestro actuar conjunto, de igual forma vivimos la urgencia de encontrar antropológicos universales que nos vinculen antes y después de las diferencias. Pero por otro, seguimos enfrentándonos, en un mundo calidoscópico, donde las diferencias son objeto de separación en momentos críticos, más que vistos como complejidad de la especie que nos enriquece:

“(...) de tal modo que nuestras concepciones actuales, propensas al universalismo, postulan un núcleo biológico, psíquico, afectivo, intelectivo y ético, que hemos llamado ya universales antropológicos, en cuya ausencia sería más que probable que las diferencias empíricas condujesen al exterminio de los más débiles por obra de los más fuertes. Y esto porque las diferencias empíricas son un a priori antropológico de todos los tiempos: diferencias de tamaño, fuerza, salud, color, o de capacidades de subsistencia"5.

Vivimos del odio y del amor, del perdón y la culpa, de la mismidad y la otredad como amenaza. Un mundo dividido en sur y norte, primero, segundo, tercero, y quinto mundo; humanistas y científicos, occidente y el resto del mundo, 
caucásicos, africanos, amerindios, asiáticos, y todo adjetivo que pone el énfasis en las diferencias que se interpretan como amenazas, indicadores de superioridad o inferioridad, pobres y ricos, gordos y flacos, industrializados y agricultores, mejores y peores. En fin nosotros y los otros. En el que siempre nos las ingeniamos para "poder" sobre el otro que no soy yo, en beneficio exclusivo mío. 0 de mi grupo, al servicio de lo cual se han puesto los más altos logros de la razón: estrategias, políticas, militares, económicas, publicitarias, propagandísticas, mediáticas. Todo al servicio del poder de unos sobre otros.

Ante tal desolador panorama que hunde sus raíces en la incapacidad de comprendernos, se ha iniciado un fuerte movimiento por encontrar puntos que nos unan y nos hermanen; rutas hacia el "comprender-nos". Algunos de estos movimientos han surgido de los ámbitos de las ciencias y la filosofía. Los que a su interior han tenido su propio debate y desacuerdo. Frente a ellos, nos hallamos, como en todos los ámbitos humanos, ante un campo de batalla, en este caos, por el monopolio de la verdad, del conocimiento. Al igual que ocurre entre las diversas naciones, culturas, religiones, etc. Pero en medio del campo de batalla, surgen voces que pueden resultar más ecuménicas, menos duras, e inflexibles. Voces sanadoras en medio del caos, quizá solo sea para una tregua mundial, pero el mundo necesita hoy más que nunca de esa tregua.

Quizá esta sea una visión escatológica, pero necesitamos ser salvados de nosotros mismos, y para ello un paso fundamental es la auto-comprensión de nuestro mundo, que somos todos y cada uno. En cuánta humanidad, cada vez más vinculada, necesitamos la capacidad de entrar en diálogo y acuerdos. Digo que este nuestro mundo urge de auto-comprensión, y responsabilidad compartida de lo que a cada uno le corresponde del caos y el orden generado, para encontrar sentidos comunes en los que podamos llegar a acuerdos y crear mecanismos que nos lleven del mal entendido, al entendimiento, pues solo nos salvamos juntos.

Necesitamos una humanidad que haga de la ética de la corresponsabilidad, fundada en la razón, su práctica social común; antes que la práctica social de la violencia cotidiana como vía de solución de nuestras diferencias y necesidades, decante hacia una norma razón ética de la irresponsabilidad y el cinismo insolidario justificado desde nuestra racionalización:

"Una última y nada desdeñable conclusión derivada de la mutua interrelación entre personas y respeto sugiere preguntarse qué sentido tiene hablar de personas y de mundo de personas, cuando el campo de la acción no esté regulado por le ejercicio del respeto y las interacciones se realizan a partir del individualismo que tiende a compendiar la Humanidad en la propia singularidad, sin tomarse, ni tomar a los demás como fines en sí mismos"6.

Digo que la separación entre mejores y peores, solo nos destruye, nos convierte no en fines en sí mismos, sino en "medios". $Y$ tales diferencias son menos 
reales de lo que parece, pues todos y cada uno podemos ser bajo circunstancias precisas bárbaros o civilizados. Buenos o malos, culpables o inocentes. Lo que debemos entender, si queremos convivir de la mejor manera, es cómo alcanzar esos ya desusados conceptos de "bien común" "persona", de la "práctica del respeto" al interior de nuestras comunidades, y entre ellas. Ello nos distingue como civilizados, como racionales, como seres éticos. Pues como dice la cita de Ricoeur que encabeza la introducción, hoy más que nunca tenemos la conciencia de que pertenecemos a una única civilización global.

Vamos a ofrecer dos ensayos de este camino hacia un saber de la comprensión. Como su historia podría remontarse hasta los exegetas griegos, chinos o hindúes, haremos un salto histórico y nos situaremos a partir de la figura de W. Dilthey y de Heidegger. La razón de situarnos desde ellos radica en que en Dilthey encontramos la radicalización de la aporía del programa hermenéutico que se inicia con Schleiermacher. Situación que colocó el saber sobre el mundo humano en un callejón intransitable y puso en tela de juicio la posibilidad de acceder a un conocimiento válido de lo humano. Dilthey, al intentar fundar la cientificidad de tales ciencias (a las que denominó como "ciencias del espíritu") en lo que él entendió como el método de la comprensión, se ve atrapado en su propio proyecto.

Veremos su camino y la paradoja a la que llega, para luego proseguir por el camino de Heidegger, pues su proyecto supuso un salto, un pasar por alto la aporía del proyecto de Dilthey, para instalarse en el ámbito de la ontología, desde una hermenéutica de la facticidad. Pero, que pese a no sortear el espinoso camino Diltheano, sienta las bases de la hermenéutica, pues la sitúa como condición existencial prístina del ser humano, al mostrar la comprensión como estructura primordial del Dasein, del -estar ahí- que somos todos y cada uno, lanzados al mundo y expuestos a él. Por tanto necesitado de comprender y comprenderse. Este camino abierto por Heidegger servirá de fundamento a la hermenéutica posterior desarrollada por Gadamer y Ricoeur.

\section{Dilthey y la fundamentación de la verdad en las ciencias sociales.}

En este punto conviene situarnos en el escenario intelectual que le tocó en suerte a nuestro personaje: el de la escuela histórica y la hermenéutica romántica y desde allí preguntarnos: ¿cómo se conecta la escuela histórica con la hermenéutica romántica?, ¿cuál es la herencia que recibe Dilthey?, y ¿hacia dónde se orienta con él la hermenéutica, y por qué?

Para responder es necesario hacer el recorrido en breve, de la situación de Dilthey y la preocupación que ocupará su pensamiento. Comencemos por citar su pensamiento directamente para conocer lo que tenía en mientes: "Nos enfrentamos ahora con la cuestión del conocimiento científico de la personas individuales, e incluso de las grandes formas de la existencia humana singular en general. ¿Es posible un conocimiento tal, y qué medios poseemos para alcanzarlo? Se trata de una cuestión del mayor alcance. Nuestro obrar 
presupone siempre la comprensión de otras personas, una gran parte de la dicha humana brota de volver a sentir estados anímicos ajenos; toda la ciencia filológica e histórica descansa sobre el presupuesto de que esta comprensión posterior de lo singular puede ser elevada hasta la objetividad. La conciencia histórica edificada sobre ese presupuesto le hace posible al hombre moderno tener presente dentro de sí todo el pasado de la humanidad: por encima de todas las barreras de su propio tiempo, mira hacia las culturas pasadas (...) Y aunque las ciencias sistemáticas del espíritu deduzcan de esta concepción objetiva de lo singular relaciones universales legales y conexiones abarcantes, los procesos de comprensión e interpretación siguen siendo el fundamento para ellas. De ahí que estas ciencias, así como la historia, sean dependientes, para su seguridad, de si es posible elevar la comprensión de lo singular a la validez universal. De este modo, en el pórtico de las ciencias del espíritu nos encontramos ya con un problema que es propio de ellas, a diferencia de todo conocimiento de la naturaleza"7.

La cita nos ubica en el problema que a Dilthey preocupa, y anuncia el camino que seguirá, así como el destino que él está pensando para la hermenéutica: un método legitimador de las ciencias del espíritu. $Y$ es que Dilthey se siente impelido a dar respuestas a los problemas que enfrenta su mundo. Para él las ciencias del espíritu constituyen la herramienta a tales problemas. Ergo es necesario replantearse el problema del conocimiento y el método científico, si se espera que desde aquéllas pueda darse respuesta a los problemas que agitan a la sociedad.

Para cuando Dilthey hace tales consideraciones en su ensayo "Dos escritos sobre hermenéutica", se han operado cambios en la concepción del saber; uno de ellos es el advenimiento de "la conciencia histórica, que domina el desarrollo de las ciencias durante la segunda mitad del siglo XIX, y desemboca en el fenómeno del historicismo. Éste surge con el deseo de explicar los fenómenos históricos a partir de sus causas y condicionamientos, con lo que diluye el problema del conocimiento en una actitud relativista". ${ }^{8}$ Otro hecho concomitante deviene de la situación de insolvencia de las opciones epistemológicas dominantes, que han arrastrado, a juicio de Dilthey, a un reduccionismo la concepción del hombre. Por un lado el positivismo ha ejercido sobre el saber una sujeción al modelo de las ciencias naturales. Camino por el cual no se ha podido avanzar en la comprensión de la naturaleza humana y sus formas de expresión en la cultura. Por otro, el idealismo trascendental y la escuela histórica también han mostrado ser un camino estéril dada la incapacidad expuesta en dar cuenta de los problemas humanos a los que se enfrenta.

Cercado por el idealismo y ello, positivismo, Dilthey emprenderá una tarea que supone superarlos; para lo cual encuentra en la hermenéutica su aliada

7. DILTHEY W: Dos escritos sobre hermenéutica: el surgimiento de la hermenéutica y los esbozos para una crítica de la razón histórica, Ediciones Istmo, S.A., Madrid, 2000, prólogo y traducción, Antonio Gómez Ramos, P. 21.

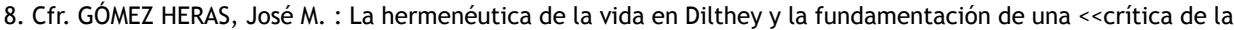
razón histórica >>, Universidad de Córdova. P. 65. 
fundamental, por lo que su giro hacia ella, estará condicionado por los intereses que a él lo mueven, esto definirá el rumbo al cual la direcciona, mientras tanto: "ve disolverse cada vez más rápido la postura filosófica del idealismo poskantiano, en el que había encontrado su expresión la visión romántica de la realidad, y la reacción que contra tal idealismo(...) llevaron a cabo en primer lugar Feuerbach y Marx de un lado y Kierkegaard del otro, y después el positivismo".

Ante tal escenario del saber, reacciona tratando de encontrar el camino que supere la desproporción de las encontradas posturas de su época. Las que considera, han conducido a un reduccionismo estéril de la realidad humana. Por ello, analiza los aportes y errores de cada postura, a fin de realizar una crítica capaz de elevarse sobre ellos.

En este proceso, será influido por la idea Kantiana de fundamentar una crítica de la razón. Lo que asumirá como su tarea. Actividad que no obstante llevará a su campo de interés: la fundamentación de una crítica de la razón histórica. Que es una manera de preguntarse y buscar solución a la pregunta sobre la posibilidad de conocimiento respecto de objetos que están más allá de la experiencia, a diferencia de los objetos de conocimientos con que trabajan las ciencias naturales, tal es el caso de los objetos de la historia del mundo humano.

Para él los beneficios del idealismo y del positivismo han fracasado por ser parciales, "puesto que no ofrecen una respuesta global al problema del conocimiento humano"10. En todo esta falencia, Dilthey observa la ausencia de una teoría del conocimiento de la historia, la cual ve clara y será el vector de su trabajo. Pero tal empresa supone un cambio en la concepción del contenido y orientación del conocer.

Para Dilthey, el primer aspecto a cambiar debía ser el contenido de ese modo de conocer que se ha enquistado de toda forma de conocer científico. Es decir, sustituir la experiencia del modo de conocer objetos de las ciencias naturales, por el modo de los objetos y experiencia de las ciencias del espíritu: "Para él la experiencia que han de abordar las ciencias del espíritu es una realidad de conciencia". ${ }^{11}$ Condición que enfrenta a una forma diferente del saber, ya que sujeto y objeto son uno. Esto que era considerado como un obstáculo epistemológico, y supone un modelo que mantiene la polaridad entre el sujeto y el objeto de conocimiento; es ahora pensado desde otro ángulo. Lo que le permite decir a Dilthey que es precisamente el hecho de ser histórico; lo que

9. IMAZ, E. Prólogo al T: I de los EE de W Dilthey, 1978; p. VII, citado en, FERNÁNDEZ F, Fernando: La fundamentación de las ciencias del espíritu en Wilhelm Dilthey; o la búsqueda de un estatuto científico para las ciencias humanas, Universidad Pontificia de Comillas, Madrid, 1986, separata, P. 11.

10. FERNÁNDEZ F, Fernando: La fundamentación de las ciencias del espíritu en Wilhelm Dilthey; o la búsqueda de un estatuto científico para las ciencias humanas, Universidad Pontificia de Comillas, Madrid, 1986, separata, P.14.

11. Ibídem. P.15. 
le confiere al investigador poder conocer la historia, por ser el mismo parte de lo que estudia:

"Las ciencias del espíritu aventajan a todo conocimiento natural en que su objeto no es un fenómeno ofrecido a los sentidos, no es un mero reflejo de algo real en una conciencia, sino que es la misma realidad interna inmediata, y lo es como una conexión vivida desde dentro. Sin embargo, ya por el modo en que esta realidad está dada en la experiencia interna resultan grandes dificultades para su concepción objetiva"12.

Esta situación no es, sin embargo, imposible para Dilthey, pues de esa experiencia ajena podemos tener noticia desde su modo de darse, en sus manifestaciones. "Lo cual se nos da, al principio desde el exterior, en hechos sensibles, en ademanes, sonidos y acciones. Para él la pregunta por el ¿cómo puede una conciencia configurada individualmente llevar (por medio de una reproducción de lo que afecta a los sentidos, una individualidad ajena, de índole totalmente diferente), hasta el conocimiento objetivo?; encuentra respuesta en un proceso que denomina comprender". ${ }^{13}$ Lo cual debe, para poder servir a tal fin, estar claramente perfilado.

En este punto, Dilthey seguirá un camino que marca su trabajo, él diferenciará entre el hacer de las ciencias del espíritu y el de la naturaleza, con lo cual introduce, por un lado su clásica separación entre ciencias del espíritu y ciencias de la naturaleza, las cuales se verán enfrentadas en un debate epistemológico en torno al método y la función que desde éste le corresponde a cada una: explicar o comprender; y por otro, introducirá una clara diferencia metodológica entre dichos quehaceres, sobre el que Gómez Heras afirma que: "establece un dualismo radical en el saber, que se corresponde con una duplicidad de contenidos y de métodos en las ciencias". ${ }^{14}$ Este dualismo sin embargo se mantendrá como un antagonismo gnoseológicamente y epistemológicamente improductivo que Ricoeur posteriormente desmántela y sustituye por el de un proceso dialéctico complementario.: “En el plano epistemológico, en primer lugar, diré que no hay dos métodos, el explicativo y el comprensivo. Estrictamente hablando, solo la explicación es algo metodológico. La comprensión es más bien el momento no metodológico que, en las ciencias de la interpretación, se combina con el momento metodológico de la explicación”"15.

Desde la tarea diltheana, la hermenéutica será concebida como un método de legitimación de las ciencias del espíritu y la dejará atada a esa condición metodológica, por tanto enajenada de una filosofía de la vida.

\footnotetext{
12. W. DILTHEY: Dos escritos sobre hermenéutica: el surgimiento de la hermenéutica y los esbozos para una crítica de la razón histórica, Ediciones Istmo, S.A., Madrid, 2000, prólogo y traducción, Antonio Gómez Ramos, P. 25.

13. Cfr. Ibídem.

14. GÓMEZ HERAS, José M. : La hermenéutica de la vida en Dilthey y la fundamentación de una $<<$ crítica de la razón histórica>>, Universidad de Córdova. P. 64.

15. RICOEUR, Paul.: Del Texto a la acción, Ed. Fondo de Cultura Económica, México,2002 P. 167.
} 
En este afán, su análisis de la condición de las ciencias, de las cuales se alimenta la ciencia histórica, descubre que ésta carece de autonomía, categorías de análisis propias y de fundamentación filosófica. Al respecto, Gadamer nos dice que, "En clara analogía con el planteamiento kantiano, también él preguntará por las categorías del mundo histórico que pueden sustentar la construcción del mundo histórico en las ciencias del espíritu" ${ }^{16}$. Para ello urge encontrar un nexo que permita integrar al sujeto y al objeto cognoscente.

Esa es la razón, por la que, nos dice Gómez-Heras, la situación descubierta y la aspiración de establecer un nexo para la historia que posibilite la comprensión del dato desde la totalidad, llevan a Dilthey a recaer en la opción romántica a favor de la experiencia subjetiva y a aproximarse posteriormente al hegelianismo. Puesto que da por sentado que el conocimiento del mundo histórico no se da a través de categorías especulativas sino en la vivencia. En ella acontece el acceso al sujeto ${ }^{17}$. Tal contexto nos sitúa en un avance y en un problema en el cual Dilthey quedará atrapado y en ello, el desarrollo de la hermenéutica.

Por otra parte, logra avanzar al deducir la hermenéutica, no desde la herencia romántica de ciencia general, sino desde la fundamentación de la filosofía de la vida. Lo dado es para él la vida misma, "para él la última realidad del mundo humano (...). La vida se analiza y se describe (...) y al hacerlo nos encontramos con una realidad concreta de la que va surgiendo todo lo humano (...). Es necesario ensanchar el esquema de compresión del individuo y de sus creaciones"18. Ello implica también concebirlo como inacabado, e histórico, por lo que no caben, para Dilthey, concepciones absolutas o reducciones abstractas y esenciales.

El Modelo de Dilthey, nos dice Gadamer, es la peculiar fusión de recuerdo y expectativa en un todo que llamamos experiencia y que se adquiere en la medida en que se hace experiencia. Las ciencias históricas solo continúan el razonamiento empezando en la experiencia de la vida. Razón por la cual el planteamiento epistemológico tiene acá un comienzo distinto: "No necesita empezar por el fundamento de la posibilidad de que nuestros conceptos coincidan con el <<mundo exterior>>. Pues el mundo histórico de cuyo conocimiento se trata aquí, es ya siempre un mundo formado y conformado por el espíritu humano. Esto lo lleva a volver sobre el principio sostenido por Vico: <<la primera condición de la posibilidad de la ciencia histórica consiste en que yo mismo soy un ser histórico >>. Idea que, hemos visto, Dilthey hace suya como presupuesto" ${ }^{19}$.

Esa concepción diltheana será posteriormente cuestionada por Gadamer. Pero bien, en ese camino de dotar con un instrumental teórico a las ciencias

16. GADAMER, H, G: Verdad y Método, Ed. Sígueme-Salamanca, 1993, P. 280.

17. Cfr. GÓMEZ HERAS, José M. : La hermenéutica de la vida en Dilthey y la fundamentación de una $<<c r i ́ t i c a ~ d e$ la razón histórica>>, Universidad de Córdova. P.68-69.

18. FERNÁNDEZ F, Fernando: La fundamentación de las ciencias del espíritu en Wilhelm Dilthey; o la búsqueda de un estatuto científico para las ciencias humanas, Universidad Pontificia de Comillas, Madrid, 1986, separata, P.28.

19. Cfr. GADAMER, H, G: Verdad y Método, Ed. Sígueme-Salamanca, 1993, P.281. 
del espíritu, Dilthey afirma, al comprender las como una de las operaciones básicas que caracterizan la especificidad de las ciencias del espíritu, su doble movimiento de ir del interior al exterior y viceversa. La comprensión, nos dice, permite el acceso a la vivencia desde su expresión externa, permitiendo el movimiento inverso, del exterior al interior. Esta necesidad de comprender es para él lo que da origen a la hermenéutica: “(...) Así, pues, llamamos comprender al proceso en el cual, a partir de unos signos dados sensiblemente, conocemos algo psíquico de lo cual son su manifestación"20.

En su trabajo, Fernando Fernández, resume las tareas de Dilthey y sus resultados en las siguientes fórmulas: La fundamentación, el camino seguido, la finalidad y su método de trabajo; "Su esfuerzo metódico queda, por tanto, dibujado como el impulso constante por descubrir las relaciones o nexos que explican los procesos y pensamiento científico-abstractos, ocultos en la realidad social pero que la sostienen y la explican; y sólo se pueden obtener, en la mediad en que se pongan en relación con las ciencias de las que han surgido, se les ubique en el contexto histórico donde se han desarrollado y se les refiere a la naturaleza humana que los ha producido"21.

Esta visión historicista y estructural es un aporte sustantivo, del que GómezHeras considera que "La posibilidad del conocimiento histórico radica para Dilthey en una estructura ontológica del hombre: su condición histórica. <<La primera condición de posibilidad de la ciencia histórica consiste en que yo mismo soy un ser histórico. Quien investiga la historia es el mismo que la realiza>>"22. Es en esta historicidad que radica el soporte de las ciencias del espíritu. Así define la vivencia, la expresión y la comprensión como los modos de operación por antonomasia del operar científico espiritual y que permitirá la dinámica del movimiento del interior al exterior de dicho modo de conocer.

Lo que vemos es pues una sustitución que anunciamos al inicio: el paso de la conciencia especulativa del kantismo, por el de conciencia histórica y el de espíritu objetivo de Hegel por el concepto de -vida-. Pese a todo su esfuerzo por encontrar en la vida una categoría fundacional, precientífica, o precomprensiva que abarca al objeto y al sujeto, eliminado el problema de la polaridad sujetoobjeto; y pese a encontrar en la hermenéutica una metodología para acceder a ese torrente de la vida, Dilthey no logra sobrevolar las atalayas del idealismo y el positivismo. Por ello no consigue superar del todo y encontrar respuesta a su pregunta sobre la fundamentación de un saber de la experiencia subjetiva.

Gómez -Heras cita tres escollos que lo llevan a fluctuar en su respuesta a la pregunta por la posibilidad de un saber objetivo de la vida: No se supera

20. W. DILTHEY: Dos escritos sobre hermenéutica: el surgimiento de la hermenéutica y los esbozos para una crítica de la razón histórica, Ediciones Istmo, S.A., Madrid, 2000, prólogo y traducción, Antonio Gómez Ramos, P. 27.

21. Cfr. FERNÁNDEZ F, Fernando: La fundamentación de las ciencias del espíritu en Wilhelm Dilthey: o la búsqueda de un estatuto científico para las ciencias humanas, Universidad Pontificia de Comillas, Madrid, 1986, separata, P. 34-51.

22. GÓMEZ Heras, José M.: La hermenéutica de la vida en Dilthey y la fundamentación de una $<<c r i ́ t i c a$ de la razón histórica>>, Universidad de Córdova. P. 68. 
coherentemente el ámbito de la vivencia subjetiva (subjetivismo) ni se sitúa el problema en una objetividad que permita tender un puente intersubjetivo.

Tampoco se elimina de raíz el relativismo inherente a la experiencia individual de la vida y de sus condicionamientos históricos en un factor de carácter absoluto. Resta por cribar científicamente la precomprensión vitalista a través de una razón crítica que articule en lógica del conocimiento la lógica de la vida $^{23}$.

Para Gadamer un paso primordial en la búsqueda de la fundamentación epistemológica de las ciencias del espíritu, dado por Dilthey lo constituye : "emprender, a partir de la construcción de un nexo propio en la experiencia vital del individuo, la transición a un nexo histórico que ya no es vivido ni experimentado por individuo alguno, pues coloca en lugar de sujetos reales, sujetos lógicos, operación en la cual no ve Dilthey problema, pues el historiador lo hace continuamente cuando habla de los hechos y destinos de los pueblos. El problema es sólo cómo se justifican epistemológicamente estas afirmaciones, advierte Gadamer"24.

En este punto Gadamer concuerda con Gómez-Heras, sobre la falta de claridad de las ideas de Dilthey. Ve problemático el paso de la fundamentación psicológica a la fundamentación hermenéutica de las ciencias del espíritu. Y la dificultad en la forma como éste entendía el fenómeno de la comprensión, la posición central que asigna metodológicamente a la expresión y la integración que realiza (en el contexto de las investigaciones lógicas), del concepto de significado que se eleva por encima de los nexos efectuales. En este sentido el concepto diltheano del carácter estructurado de la vida psíquica se corresponde con la teoría de la intencionalidad de la conciencia en cuanto que ésta describe fenomenológicamente, no solo un hecho psicológico, sino una determinación esencial de la conciencia ${ }^{25}$.

Para Gadamer, esta integración, le permitirá a Dilthey decir hasta qué punto el nexo estructural de la vida está dado, y por otro, permite una nueva fundamentación del concepto de lo dado, que tendrá en las ciencias del espíritu una estructura completamente distinta, pues todo lo dado es allí producido.

Pese a esa ganancia. Se pregunta nuevamente Gadamer, si se logra el paso de lo psicológico a lo hermenéutico. Para Gadamer, el intento lleva a Dilthey a regresar a los puertos de salida de donde pretende escapar. Lo que conduce a inquirir por la diferencia entre la postura que asume y el idealismo del que huye. Al respecto y con ironía Gadamer dice, “¿si no habría que preguntar, sino habrá también para Dilthey una forma del espíritu que sea verdadero

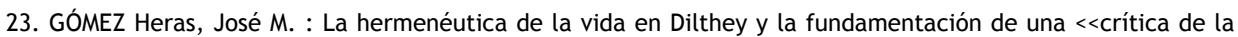
razón histórica >>, Universidad de Córdova. P.70.

24. GADAMER, H, G: Verdad y Método, Ed. Sígueme-Salamanca, 1993, P.284.

25. GADAMER, H, G: Verdad y Método, Ed. Sígueme-Salamanca, 1993, P.284, 
<<espíritu absoluto>>, esto es plena autotransparencia, total cancelación de toda extrañeza y de todo ser otro"26.

En este punto vemos que finalmente Dilthey no soluciona satisfactoriamente el problema de la objetividad del saber histórico con que da inicio su esfuerzo, y Gadamer nuevamente pregunta ¿si no será la conciencia histórica un ideal utópico que contiene en sí mismo una contradicción?

Por lo que vemos Dilthey, atrapado, recurre a una transposición de conceptos con ecos del idealismo. De ello, Gadamer sostiene que "el resultado fue que al final la historia quedó reducida a historia del espíritu, reducción que Dilthey admite de hecho en su media negación y media afirmación de la filosofía hegeliana del espíritu, y la hermenéutica reducida a un instrumento. "Era un médium universal de la conciencia histórica. Todo en la historia es comprensible, pues toda en ella es texto (...) De este modo Dilthey acaba pensando la investigación del pasado histórico como desciframiento y no como experiencia histórica"27.

Hasta acá hemos respondido a las preguntas por ¿cuál es la herencia que recibe Dilthey?, y ¿hacia dónde se orienta con él la hermenéutica, y por qué? Desbrocemos ahora nuestra última duda: ¿cómo se conecta la escuela histórica con la hermenéutica romántica?, y conectemos la situación para comprender el estado en que queda la hermenéutica y el giro que experimentará.

Al respecto volvemos nuestra mirada a Ricoeur, quien nos dice, en Del texto a la Acción, que, una de las dificultades de la hermenéutica romántica fue la disociación entre explicar y comprender. Ello exige una reorientación de la hermenéutica en el plano epistemológico que le demanda a la hermenéutica la noción de texto. Para él la historia reciente de la hermenéutica ha estado dominada por dos preocupaciones ${ }^{28}$ : el movimiento de regionalización o la ampliación progresiva de su alcance y el movimiento de radicalización, mediante el cual, nos dice Ricoeur, la hermenéutica no solo se vuelve general sino también fundamental.

Ya la hermenéutica de Schleiermacher, tal cual, implicaba una aporía en su programa, derivado de los dos tipos de interpretación que involucra para la comprensión de las diferentes situaciones. Así, la dificultad de separar las dos hermenéuticas se complica, dice Ricoeur, pues, porque al primer par de opuestos, lo gramatical y lo técnico, se superpone un segundo par de opuestos, la adivinación y la comparación. Para Ricoeur, su obra, Los discursos académicos, se pone de manifiesto esta extrema dificultad del fundador de la hermenéutica moderna.

Para Ricoeur, las dificultades señaladas, solo pueden superarse si se aclara la relación de la obra con la subjetividad del autor y si, en la interpretación, se

28. Cfr. RICOEUR, Paul: Del Texto a la Acción, Fondo de Cultura Económico, México, 2002, P. 76. Título original, "Du texte à l'action. Essais d'herméutique I". 
desplaza el acento de la búsqueda patética de subjetividades ocultas hacia el sentido y las referencias de la obra misma.

Pero, antes es necesario llevar la aporía central de la hermenéutica más lejos, considerando la ampliación decisiva que ha llevado a cabo Dilthey al subordinar la problemática filosófica y exegética a la problemática histórica, “(...) esta mayor universalidad, prepara el desplazamiento de la epistemología hacia la ontología en el sentido de una mayor radicalidad"29. En esta línea entronca con la idea de Gadamer de la necesidad que el esfuerzo de Dilthey pone al descubierto, a saber, la de que "la tarea no puede ser otra que la de describir más adecuadamente la experiencia operante en las ciencias del espíritu y la objetividad que en ellas pueda alcanzarse" ${ }^{30}$.

Para Ricoeur, Dilthey logra situar la amplitud del problema de la hermenéutica. El problema radica en que continúa todavía planteada en los términos del debate epistemológico característico de todo el período neokantiano. Y pese a que le pisa los talones, al camino correcto, en lugar de buscar la clave en la ontología, dice Ricoeur, se vuelca a una reforma de la propia epistemología, lo que se manifestó a su juicio como el hecho cultural del ascenso del positivismo como filosofía 31 .

Su contexto, como lo hemos visto, no le permitió a Dilthey apartarse del único modelo aceptado como científico y centró todo su reflexión y finalidad, en lo que cree, y que le permitiría a las disciplinas del espíritu elevarse a la categoría de ciencias, como dice Ricoeur, dotarlas de una metodología y epistemología respetables.

Con este apartado hemos descrito el escenario que rodea el siguiente movimiento del devenir de la hermenéutica, su giro ontológico. Para Ricoeur, la obra de Dilthey más que la de Schleiermacher pone de relieve la aporía central de la hermenéutica, ya que nos dice:

"que coloca la comprensión del texto bajo la ley de la comprensión de alguien diferente que allí se expresa (...) el objeto de la hermenéutica constantemente es desviado del texto, de su sentido y de su referencia, hacia la vida, con su profundo irracionalismo, y una filosofía del sentido, que tiene las mismas pretensiones que la filosofía hegeliana del espíritu objetivo. Dilthey ha transformado esta dificultad en axioma". 32

\section{El giro ontológico de la hermenéutica: Heidegger.}

Hasta acá, hemos observado que la hermenéutica se encuentra atascada en un paradigma que la condiciona y arrastra hacia él, como agujero negro que atrae a todo objeto que se acerque a sus límites.

29. Ver esta relación en. RICOEUR, Paul, 2002, P.76

30. GADAMER, H, G: Verdad y Método, 1993, 304.

31. Cfr. RICOEUR, Paul: Del Texto a la Acción, P. 77. I".

32. RICOEUR, Paul: Del Texto a la Acción, P. 81. 
El esfuerzo de Dilthey, como hemos visto, no ha podido justificar las ciencias humanas, para llevarlas al mismo nivel de las ciencias naturales. Se encuentra como hemos visto empantanado en el cartesianismo del que no se ha liberado del todo y permanece atrapado en el problema de un método que por principio no se puede igualar, pues la naturaleza del objeto es diferente. Al respecto la fenomenología de Husserl, ha retornado al camino que inició Dilthey: la vida misma. Este tema es, a diferencia del epistemológico afincado en el método, un tópico de carácter universal. Husserl, maestro de Heidegger, situará en ese mundo de la vida (común y anónimo, por ser el espacio de todos) el horizonte de "la constitución de todo sentido y de toda la significación que forma el suelo y la textura de la experiencia" 33 .

Sus análisis del mundo de la vida nos muestran la experiencia de las ciencias naturales, como un sistema de significaciones más, dentro de un engranaje de sentidos. Por tanto, determinado por su intencionalidad, de modo que la objetividad que reclaman, es un caso singular dentro los diferentes modos de intencionalidad del mundo de la vida.

Para Husserl, es necesario separar el ser histórico del ser de la naturaleza, en donde "el mundo del conocimiento que es el de las ciencias es una especie de derivado de la comprensión" 34 .

¿Cómo, entonces, se llega a una ontología de la comprensión, desde una epistemología de la interpretación?, se pregunta Ricoeur ${ }^{35}$. Para este autor, existen dos maneras de fundar la hermenéutica en la fenomenología, una que llama la vía larga y otra la vía corta. Esta última es la que a su juicio sigue Heidegger en su Analítica del Dasein. En ésta, se salta todo el problema del método y se instala inmediatamente: "en el plano de una ontología del ser infinito"36.

Desde este proceder, Heidegger desplaza el problema del comprender como modo de conocimiento (tal cual ha sido la marea en la que se ha sido afrontado), hacia el comprender como "un modo de ser". Por tanto, sostiene Ricoeur: "No se ingresa de a poco en esta ontología de la comprensión, no se accede a ella gradualmente, profundizando las exigencias metodológica de la exégesis, de la historia o del psicoanálisis: nos transportamos en ella por una súbita inversión de la problemática"37.

Esta inversión es precisamente el giro operado por Heidegger, un abrupto cambio que supone saltar por encima de la pregunta sobre las condiciones necesarias para que un sujeto pueda comprender, a la radical pregunta de: ¿qué es un ser cuyo ser consiste en comprender? Entroncamos acá con la hermenéutica vital,

33. GADAMER, H. G.: El problema de la conciencia histórica, Madrid, 1993, P. 32.

34. Op. Cit., P.71- 72.

35. RICOEUR, Paul : El conflicto de las interpretaciones, 2003, P. 12.

36. Op. Cit., P. 11.

37. Ibídem. 
que Heidegger descubre en su análisis del -ser ahí- del Dasein. De la situación del hombre concreto, fáctico, en su condición de -estar ahí- No de un sujeto trascendental, abstracto, sino en su concreción fáctica. De este modo, nos advierte Ricoeur, "El problema hermenéutico se convierte así en una región de la Analítica de ese ser, el Dasein, que existe al comprender" ${ }^{38}$. Éste será, como veremos, el gran descubrimiento de Heidegger.

Al respecto, Gadamer señala que, "en Heidegger asistimos a una valoración ontológica del problema de la estructura de la comprensión histórica, fundada sobre la existencia humana que está orientada esencialmente hacia el futuro". ${ }^{39}$ Es decir pro-yecto nos dirá Heidegger en Ser y tiempo; y proyecto desde su condición originaria del de-yecto ${ }^{40}$ (lanzado a la vida, expuesto al mundo). Proyecto para el cual es inherente el saber de sí, preguntar por su -sí mismo- como poder para proyectarse, para ser. Acá comprender, como vemos, no es más un camino de fundamentación para obtener información y certeza de un saber, es un modo de ser que consiste en saberse en tanto poder ser.

Para comprender la hondura y radicalidad de este giro, es necesario situarlo desde sus fuentes y desplegarlo desde allí. Recordemos las implicaciones y complicaciones a las que Dilthey había llevado a la hermenéutica, al asignarle la función de metodología de las ciencias del espíritu y las consiguientes aporías de allí derivadas. Recordemos además que su intención original parte del feliz intento de ir a las cosas mismas, a la vida concreta, pero no lo consigue. Pese a que ha logrado, como observa Gadamer, enlazar con las ideas de la fenomenología de Husserl y dar con el nudo del problema: “El momento en que Dilthey enlaza con las investigaciones lógicas de Husserl afecta sin duda al tema nuclear. Al respecto Ricoeur nos dice, "Sin embargo, Dilthey ha percibido perfectamente el nudo central del problema: la vida solo puede captar la vida por la mediación de las unidades de sentido que se elevan por encima del flujo histórico (...). Pero para dar continuidad a este hallazgo, habrá que renunciar a vincular la suerte de la hermenéutica con la noción puramente psicológica de transferencia (...) ya no hacia su autor, sino hacia su sentido inmanente y hacia el tipo de mundo que él abre y descubre" ${ }^{41}$.

Gadamer por su lado, observa de igual manera que la idea de la fenomenología se encuentra en las investigaciones lógicas con las que Dilthey enlaza: “(...) esto es, la desconexión de toda forma de <<poner el ser>> y la investigación de los modos subjetivos de estar dadas las cosas, y se hacía de esto el programa universal de trabajo, encaminado a hacer comprensible toda objetividad, todo sentido óntico. Sin embargo la subjetividad humana posee validez óntica (...) también ella debe ser investigada en toda su variedad de los modos de estar dada"42. "Esta reflexión de un yo como fenómeno, representa la aparición de una

38. Ibídem.

39. GADAMER, H. G.: El problema de la conciencia histórica, P. 75

40. El sentido original del término se refiere a la forma en que las gatas paren a sus crías.

41. RICOEUR, Paul: Del Texto a la Acción, P. 82

42. GADAMER, 1993, P.308. 
nueva dimensión (...) Pues hay un modo de estar dado que no es a su vez objeto de actos intencionales. Toda vivencia prosigue Gadamer, implica horizontes anteriores y posteriores y se funde en última instancia con el continuun de las vivencias presentes de antes y después, en la continuidad de la corriente vivencial" 43 .

Las Investigaciones Lógicas, de Husserl, a juicio de Gadamer, son el intento de comprender el modo de ser de la conciencia del tiempo. Desde allí, toda investigación fenomenológica se entenderá como investigaciones de la constitución de unidades de y en la conciencia del tiempo, que a su vez presuponen la conciencia temporal. Y por ende toda vivencia intencional implica más bien un horizonte vacío de dos caras, aquello a lo que la vivencia no se refiere, pero puede orientarse, y el todo de tales vivencias tematizable. La corriente vivencial posee el carácter de una conciencia universal del horizonte del cual realmente sólo están dados momentos individuales -como vivencias-.

Husserl ha dado con aquello que es el suelo de toda intencionalidad y sentido: la vida que es temporal, la temporalidad y la conciencia de la misma. De la cual la vivencia es un horizonte.

Para Gadamer, ese concepto de horizonte, posee un significado fundamental para las investigaciones fenomenológicas de Husserl; como horizonte conforma un espacio flexible que se desplaza con uno, y agrega que cuando Husserl, deja a tras el concepto de conciencia subjetiva y lo sustituye por vida, deja entrever que pretende retroceder más atrás de la actualidad de la conciencia referente y de la potencialidad de la connotación. Retroceder que lo lleva hacia una intencionalidad básicamente anónima, que no es producida ya nominalmente por nadie y por ende constituye el horizonte del mundo que lo abarca todo, En este camino, Husserl se coloca en contrapuesta a un concepto del mundo que abarca el universo de lo que es objetivable por las ciencias. Por tanto apunta a lo que luego verá Heidegger como el momento fundacional pre-teorético.

A ese mundo llama Husserl, <<mundo vital $>>$ y representa el suelo previo de toda experiencia y como fenómeno horizóntico este $<<$ mundo >> está esencialmente referido a la subjetividad y por tanto de los <<encada caso $>>$, por lo que se encuentra en un movimiento de constante relativización de la validez, que se opone a todo objetivismo. Es un concepto esencialmente histórico, dice Gadamer, quien ve en ello un punto en acuerdo con Dilthey, éste, lejos de retroceder al sujeto epistemológico como vimos, había intentado retroceder hasta la unidad de la vida como núcleo u horizonte. Al $<<$ punto de vista de la vida $>>$ y de una forma muy parecida, sostiene Gadamer, la $<<$ vida de la conciencia >> de Husserl ${ }^{44}$.

Este concepto de mundo vital encierra una paradoja, que Husserl considera aparente, nos dice Gadamer, a saber: supone ya un mundo comunitario que 
contiene la coexistencia de otros, al refiere al todo en el que estamos viviendo los que vivimos históricamente, y es por tanto un mundo personal en el que está presupuesta la validez natural, pues de ella participamos todos y cada uno.

Pero, Gadamer se pregunta: ¿cómo se fundamenta esa validez partiendo de un rendimiento de la subjetividad? Entonces qué condición puede garantizarnos la validez de un saber individual. Un problema sobre el que Husserl ha reflexionado incansablemente, afirma Gadamer y que lo lleva al cambio que se opera en él, y que radica en el reconocimiento de la necesidad de "el ir a las cosas mismas", las que nunca son independientes de la conciencia, sino en virtud de su intencionalidad, ésta según su origen es una categoría hermenéutica, aunque, nos dice Grondin, Husserl habla rarísimas veces de la hermenéutica.

El concepto de intencionalidad en Husserl, deja ver, observa Grondin, que no hay objetividad o apertura del objeto sin intencionalidad constitutiva de la conciencia. Sobre este concepto Gadamer tiene especial interés, pues como dice Grondin, señala que toda intencionalidad se inscribe en el marco de una visibilidad, que o puede ser completamente temático sin significar con ello un límite rígido. Porque el horizonte se mueve junto con nosotros ${ }^{45}$. Es decir vemos desde la intencionalidad que enraíza en nuestro horizonte y es nuestro horizonte, nuestro visor.

Pero el caso es que el yo que reflexiona sabe que vive en determinaciones de objetivos respecto de los cuales el mundo vital es la base y fundamento. Por tanto es acá donde la tarea de una constitución del mundo vital resulta paradójica, lo que a Husserl resulta aparente.

Para Gadamer, Husserl “no es lo suficientemente radical, porque sigue hablando paradójicamente de una constitución del mundo de la vida, que habría que reducirse a un yo <<originario>>. En este punto no se había desligado de esquemas de pensamiento idealistas y epistemológicos" ${ }^{46}$.

Lo que observamos sin embargo, es que en esta posición, Husserl sigue girando en la noria de una búsqueda de validez del conocimiento. Entonces, ¿qué avanza Husserl respecto a Dilthey y qué aporta a Heidegger en su radical al giro ontológico?

Veamos al respecto lo que nos señala Gadamer: “También Heidegger está determinado en sus comienzos por aquella tendencia común a Dilthey y a York, que uno y otro formularon como <<concebir desde la vidas>, así como por la que se expresa en la vuelta de Husserl, por detrás de la objetividad de la ciencia, al mundo vital. Sin embargo, Heidegger no se ve alcanzado por las implicaciones epistemológicas según las cuales la vuelta a la vida (Dilthey),

45. Cfr. GRONDIN, j.: 2003, P.121-122.

46. Op. Cit., P.122 
al igual que la reducción trascendental (la autorreflexión radical de Husserl), tienen su fundamento metódico en la forma como están dadas las vivencias por sí mismas. Esto es más bien el objeto de su crítica" ${ }^{47}$.

Husserl, maestro de Heidegger, en su fenomenología trascendental comprende el proceso de: "ir a las cosas mismas, al mundo de la vida", luego Heidegger diría en sus cátedras: "Mundanea". Entonces la pretensión, es partir de la experiencia pura, desde las cosas en tanto que se nos presentan como fenómeno y despojadas de cargas conceptuales. Esto es posible por un procedimiento descriptivo no explicativo, por medio del cual se capta la idea, el eidos

Pero al situar dicho proceso en el análisis de la conciencia y de su la intencionalidad, deja las cosas mismas olvidadas y se recluye en una abstracción: un yo absoluto, posición de la que ha intentado escapar. Por lo que su fenomenología queda adscrita al ámbito de lo trascendental. Con ello se aleja de su proyecto original. Al respecto y sobre un tema en torno a la dinámica del texto, Ricoeur nos hace el llamado sobre la fenomenología y su origen en la idea de intencionalidad en Husserl y las limitación y apertura que desde allí ofrece: “(...) a pesar de haber nacido con el descubrimiento del carácter universal de la intencionalidad, la fenomenología no ha seguido el consejo de su propio hallazgo, es decir que la conciencia tiene su sentido fuera de sí misma (...) El modo radical de poner término a esta confusión que reaparece una y otra vez es desplazar el eje de la interpretación del problema de la subjetividad al del mundo" ${ }^{48}$.

En Heidegger lo que ocurre es una radicalización del proyecto de su maestro, fiel a él y con todo un contexto, tras sus espaldas y sobre ellas, que hemos venido rodeando, acontece un giro de lo fenomenológico a lo hermenéuticoontológico. De allí que lo que vemos es un camino que va de la fenomenología trascendental de Husserl a una la analítica existencial del "ser ahí", del Dasein. Con lo que se inaugura una ontología hermenéutica.

Lo que advertimos acontecer en Heidegger, no es ya el desarrollo de una fundamentación hermenéutica, sino un proceder fenomenológico-hermenéutico, es decir un camino de comprensión al ser, que es un análisis del modo de ser mismo.

En el punto en que su maestro sitúa el proceder de las ciencias naturales como una singularidad derivada de la comprensión, nos dice Gadamer, Heidegger "comprende" que la compresión es algo más que lo que conciben Dilthey y Husserl, es la forma original, (y he aquí el giro), de realizarse el -estar-ahíhumano, en tanto que ser- en -el- mundo (...), el comprender es este modo de ser del estar-ahí que constituye a aquel en <<saber-ser >> y posibilidad > $>49$.

47. Cfr. GADAMER, H.G.: Verdad y método, 1993 P.319

48. RICOEUR, Paul: Del texto a la acción, P. 52.

49. Cfr. GADAMER, H. G.: El problema de la conciencia histórica, P.72 
En esta posición de Heidegger, observamos un camino nuevo trazado por la preocupación que lo mueve, y es que se ha situado en los principios anteriores a Parménides, y lejos de dar por hecho el ser y construir sobre una premisa dada, toda una teoría, recupera la pregunta olvidada para toda la filosofía occidental, y no da por hecho, sino que se pregunta qué es lo que hay. Esta pregunta lo lleva a descubrir la nada como posibilidad. En este preguntar por el ser, se articula lo que la metafísica griega esquivo; la nada.

Entonces desde esa posibilidad, emerge su gran preocupación: el camino de acceso al "ser"; que es precisamente el camino del que se ha estado resbalando la hermenéutica al restringirla como vía al conocimiento. "El camino filosófico de Heidegger tuvo a la vista desde sus primeros escritos la pregunta por el ser en forma hermenéutico-fenomenológica" ${ }^{50}$. El la preocupación del joven y del Heidegger posterior al "Ser y tiempo", el pensador que se abre a la verdad de la experiencia del arte y del lenguaje. "Ser y tiempo será un paso previo, un interludio en el cual descubre la estructura del estar-ahí, del Dasein.

Para el joven Heidegger, su caminar parte del preguntar por ¿cuál es la tarea de la filosofía? Una pregunta angustiante que se formula desde su cátedra en medio de la artillería de la I Guerra Mundial, la cual aún asoma como un terrorífico fantasma. Cuando en 1927 se publica Ser y Tiempo, ha pasado menos de una década, pero lo suficientemente rica, para que esté plenamente convencido de la necesidad de radicalizar en el camino de la vida y su sentido de la experiencia pura, pre-teorética y al margen de la pretensión científica metodológica. Sobre toda esta crítica a la ciencia y al saber teórico nos dirá tempranamente ((1919): "ahora resulta comprensible hasta qué punto la motivación de lo formalmente objetivo es cualitativamente distinta de la motivación de lo específicamente objetivo y cómo lo primero se retrotrae al mismo tiempo a un estrato fundamental de la vida en y para sí. Por tanto, no es necesario que lo significativo (117) la expresión verbal, se piense sin más en términos teoréticos u objetivos, sino que es originariamente vivida y experimentada en un sentido premundano o en un sentido mundano" 51 . Este sentido anunciado se torna fundacional ya que en él encuentran unas funciones que: "expresan la vida en las tendencia que la motivan y en las motivaciones hacia las que tiende(...)La vivencia que se apropia de lo vivido es la intuición comprensiva, la intuición hermenéutica, la formación originariamente fenomenológica que vuelve hacia atrás mediante retroconceptos y que anticipa con ayuda de preconceptos y de la que queda excluida toda posición teorético-objetivante y trascendente, la universalidad del significado de las palabras señala primariamente algo originario: el carácter mundano de la vivencia vivida"52

50. XOLOCOTZI, Ángel: Fenomenología de la vida fáctica. Heidegger y su camino a Ser y tiempo, México,Plaza y Valdés/Universidad Iberoamericana, 2004, P. 202, citado en: Signos Filosóficos, vol. VIII, núm. 15, enero-junio, 2006, pp. 189-193,

51. HEIDEGGER Martín: La idea de la filosofía y el problema de la concepción del mundo, Ed. Herder, Barcelona, 2005, P. 141.

52. Op. Cit., 2005, P. 141-142. 
Ahora conviene preguntarse por la importancia del giro heideggeriano y sus descubrimientos, uno de los cuales será la estructura del Dasein, su finitud y la condición del deyecto en que se encuentra. Aquella condición existencial de la que hablamos al inicio, la una hermenéutica como un modo vital.

Este nuevo horizonte que comienza a trazar descubrirá el carácter deyecto y proyecto del estar-ahí; en el que la comprensión es la manera de estar sabiendo de sí, no como dato, sino como poder moverse, manejarse entre las cosa del mundo. Estas ideas las encontramos en los escritos tempranos de Heidegger.

Para J. Grondin, la hermenéutica más antigua de Heidegger subyace en dichos escritos temprano. Para ser exactos en sus cursos de 1923, los de su "Hermenéutica de la facticidad". Allí se pregunta por las vías de acceso al ser, no en su modo teórico, sino en su ser real: la que es concreta en cada caso, no por objetivación, ni abstracción. La existencia, su propio ser, o estructura de ser es "ahí." Un ahí único y propio, posible en cada caso concreto del ahora. Que consiste en ser el mismo -ser- y por tanto que no puede ser objeto de un tener. Pues de lo que se trata es de un estar siendo. No puede ser tenido, pues ya no es lo tenido, sino lo que está siendo en el siguiente instante posterior a lo tenido.

Es por tanto un -cómo- que es siendo vigilia, no cesa. Es un siendo en la forma en que puede serlo desde su propia forma de ser. La vida es por tanto una forma de ser de - la forma propia en que el ser ahí puede ser. Por lo que fáctico es ese ser concreto, real en su modo de ser propio: "ser ahí", que es articulación desde sí mismo.

Vida fáctica es pues nuestra propia existencia en cuanto que-ahí-. Ahí manifiesta que la hermenéutica tiene la tarea de hacer accesible la propia existencia y comunicárselo. Desocultar la extrañeza de la que la propia existencia viene afectada. La hermenéutica ofrece la posibilidad a la existencia de convertirse en entendiente para sí. Acá vemos un carácter que luego Gadamer retoma en su idea de la vigilancia de la conciencia histórica efectual.

En Ser y Tiempo, Heidegger, nos dice que además, la hermenéutica es un encontrarse: "El fundamento de la interpretación está en que cada caso en un comprender que es siempre también un encontrarse, es decir un estado de ánimo, un modo de estar." 53 He aquí el punto clave de su descubrimiento en abono a la hermenéutica, pues descubre la interpretación como un modo connaturalmente humano, ya no algo secundario, o nota adventicia, sino, descubre que la interpretación, el saber de sí es Sine qua non posibilidad humana, sí y solo sí. En Ser y Tiempo, Heidegger nos sitúa en la estructura fundamental del ser ahí, que es: "El ser en el mundo", Del que realiza su análisis de las estructura del - ser en- y el -ser ahí-, en el horizonte de la temporalidad 
que le es propia y de la cual escapa y se oculta de múltiples formas. En ellos analiza los diferentes estatutos, modalidades, situaciones del ser ahí, sus autoengaños existenciarios y nos lleva al estar- ahí como comprender, en su modo de apertura ser proyectivo, como modo de ser posibilidad de ser, en el horizonte de ser histórico ${ }^{54}$.

Es decir, como propone Gadamer, apertura temporal, pero desde el desmontaje de ese concepto "vulgar de tiempo" en que la filosofía, incluso la de Hegel viene montada. Para Gadamer un logro fundamental es reconocer con Heidegger que el tiempo acá no es un dato, un concepto, es tiempo original, concreto. Por ello, ser es temporalidad: "el conocimiento histórico no es un tipo de proyecto de planificación, ni extrapolación de fines queridos, ni todavía la disposición de las cosas según el buen querer, prejuicios vulgares o sugestiones de un tirano(...), no se trata de un ente mensurable o constatable, sino aquella relativa al modo de ser del estar-ahí humano. Pero esto no debe entenderse como homogeneidad entre sujeto cognoscente y lo conocido, ambos son históricos, es decir que tiene el modo de ser de la historicidad ${ }^{55}$.

El comprender es para Heidegger una capacitación que posibilita el proyecto del -estar-ahí-, no una operación teorética ulterior a la vida.

Esta forma de temporalidad, que es tiempo original, que se revela en la exégesis ontológico-existenciaria del todo original del "ser ahí" fáctico, es para Heidegger el sentido del ser de la cura, para el mal de escaparse y resistir de su condición real y no hacerle frente y caer en el estado de perderse. Actitud que reconoce en la tendencia al encubrimiento del más peculiar "ser relativamente a la muerte" 56 .

Para él, la cura es el estado de desembozar la totalidad de ese todo estructural que decanta en el "estado abierto" como el fundamento temático del "ser en el mundo" y su esencia: la existencia, es decir que el "ser ahí" es la forma de un "poder ser" comprensor al que en su ser le va este mismo" 57 . La exégesis ontológica que él busca, no es la del ser en general, pues no es posible la una sin la otra, la una reclama la exégesis original del "ser ahí". Y esa exégesis original es la cura del "ser ahí." Esta investigación ontológica la entiende como: "una especie posible de la interpretación, que se caracteriza como articulación y apropiación de un comprender. Toda interpretación tiene su "tener previo", su "ver previo" y su concebir previo". Si como exégesis se torna problema expreso de un estudio, entonces ha menester el todo constituido por esos "supuestos", todo que llamamos la situación hermenéutica"58. Este es para él un tener previo, al que deben ajustarse todos los pasos ulteriores del análisis.

54. Cfr. HEIDEGGER, Martín: Ser y Tiempo, 1997, P.276-77.

55. GADAMER, H. G.: El problema de la conciencia histórica, P. 72-76.

56. HEIDEGGER, Martín: Ser y Tiempo, 1997, P. 277.

57. Op. Cit, P.253.

58. Po. Cit., P.254. 
Un problema que enfrenta la exégesis ontológica es que "El ente cuya esencia está constituida por la existencia, se resiste esencialmente a la posibilidad de que se lo aprehenda como un todo. La situación hermenéutica no sólo no se ha asegurado hasta aquí el "tener" el ente todo, es dudoso incluso si es ello asequible y si una exégesis ontológica original del ser ahí no tendrá que estrellarse contra la forma misma de ser del ente temático"59.

Esto dice, Heidegger, solo será posible si se opone a la luz el ser del "ser ahí" en su posible totalidad y propiedad. Es así como surge el problema de ir más allá del "tener previo," lo que implica tener el "ser ahí" como un todo, y desarrollar la cuestión del "poder ser total”. Esto lleva a lo que está antes y después del momento del puntual ser ahí: pasado o historia, futuro o proyección. La estructura temporal del despliegue del poder del ser ahí, que es su modo de ser propio de cara a "ser relativamente a la muerte". Ese poder ser total se hace vivible como modo de la cura, a través del análisis que pone al descubierto el fundamento óntico original: la temporalidad.

Como vemos Heidegger, tras un proceso de análisis va desplegando no una teoría, sino un proceso hermenéutico que nos instala inmediatamente en la estructura del ser y su comprensión como ser que se interroga así mismo y se oculta y por tanto demanda una comprensión permanente en su estar siendo. Esto está condicionado como hemos visto por lo que se proponía: “La fenomenología hermenéutica de Heidegger y el análisis de la historicidad del -estar ahí-(...) se proponía más que una teoría de las ciencias del espíritu o una superación de las aporías del historicismo gracias a la radicalidad de su planteamiento pudo salir del laberinto en el que se habían dejado atrapar las investigaciones de Dilthey y Husserl sobre los conceptos fundamentales de las ciencias del espíritu"60.

Así, desde una hermenéutica de la facticidad de estar-ahí, Heidegger les plantea lo que debe erigirse en base ontológica del planteamiento fenomenológico, y no el puro <<cógito>, dirá Gadamer en el capítulo que le dedica en Verdad y método ${ }^{61}$.

Heidegger recoge en este momento a un Kierkegaard procedente de la crisis espiritual del hegelianismo. Crítica que entonces y hoy tropezaba con la muy abarcante pretensión del planteamiento trascendental. $Y$ esto vale para el planteamiento trascendental a cuya sombra había formulado Husserl la tarea universal de la fenomenología: la constitución de toda validez óntica. Evidentemente esta tarea tenía que incluir la facticidad que Heidegger pone en primer plano, nos advierte Gadamer.

Ahora veamos que se gana en este proceder heideggeriano. Para ello seguiremos a Gadamer en el análisis que realiza de Heidegger en Verdad y método y la relación que le antecede en El problema de la conciencia histórica ${ }^{62}$.

59. Op. Cit., P.255.

60. GADAMER, H.G.: Verdad y método, 1993 P. 324.

61. Op. Cit., P. 319.

62. Para ver detalles, remitimos a las páginas 319 a 327 de Verdad y Método y a las Págs. 71 a 80 del problema de la conciencia histórica. 
Gadamer nos recuerda que Husserl ya se había planteado la problemática de las paradojas que surgen en el desarrollo de su solipsismo trascendental. Por eso no es objetivamente fácil señalar el punto desde el que Heidegger podía plantear su ofensiva al idealismo fenomenológico de Husserl. Incluso, sostiene Gadamer, hay que admitir que el proyecto heideggeriano de Ser y tiempo no escapa por completo al ámbito de la problemática de la reflexión trascendental. Su pregunta y fundamentación por el -estar ahí-, parecía en principio desarrollar tan solo una nueva dimensión de cuestiones dentro de la fenomenología trascendental.

También Husserl había pretendido que todo sentido del ser y de la objetividad solo se hace comprensible y demostrable desde la temporalidad e historicidad del estar ahí. Esto es desde la historicidad absoluta. Para Gadamer, la diferencia respecto de Heidegger, se hace clara en los precedentes de Husserl. Su crítica a ellos supone una prosecución metódica y se entendía como tal, por el contrario lo que Heidegger intenta tiene más bien que ver desde el principio con una teleología de signo inverso.

Por supuesto, para cuando aparece "Ser y tiempo" estaba admitido que este recurso a lo más antiguo era al mismo tiempo un progreso respecto a la posición de la filosofía contemporánea. $Y$ no es sin duda arbitrario que Heidegger asuma entonces las investigaciones de Dilthey y las ideas de York en su propia continuación de la filosofía fenomenológica. El problema de la facticidad era de hecho también el problema central del historicismo, al menos bajo la forma de la crítica a los presupuestos dialécticos de la razón, en la historia elaborada por Hegel.

El proyecto heideggeriano, sostiene Gadamer, de su ontología fundamental tenía que traer a primer plano el problema de la historia. Pero no tardó en mostrarse que ni la solución al problema del historicismo o la fundamentación originaria de las ciencias, incluida la ultrarradical de Husserl, constituirían el sentido de esta ontología fundamental; es la idea misma de la fundamentación la que experimenta ahora un giro total.

La temporalidad no es ya la de la <<conciencias> o la del yo originario trascendental. La estructura de la temporalidad aparece así como la determinación ontológica de la subjetividad. El ser subjetivo, está condicionado, por ser histórico, temporal. Pero es algo más. La tesis de Heidegger sostiene que el ser mismo es tiempo. Con esto se rompe todo el subjetivismo de la nueva filosofía, incluso todo el horizonte del problema de la metafísica, encerrado en el ser como lo presente. El planteamiento que en "Ser y tiempo" está en cuestión es el hecho mismo de que exista un ahí, una pre- esencia fundacional del sentido; pero lo que anuncia Heidegger es la nada, un claro en el ser; esa es la diferencia entre ente y ser.

Heidegger, señala Gadamer, apuntó al olvido de ese preguntar por el ser, hacia lo que se ocultaba y estaba silenciada en la pregunta metafísica del ser: el 
malestar ontológico que provoca en este pensamiento el problema de la nada. Y en cuanto se pone de manifiesto que esta pregunta por el ser es al mismo tiempo la pregunta por la nada, reúne el comienzo y el final de la metafísica. El que la pregunta por el ser pueda plantearse desde la pregunta por la nada presupone ya ese pensamiento de la nada ante el que había fracasado la metafísica.

Esta es la razón por la que el verdadero precursor de la posición heideggeriana en la pregunta por el ser y en su remar contra la corriente de los planteamientos metafísicos occidentales no podía ser ni de Dilthey ni de Husserl, sino en todo caso Nietzsche.

Para Gadamer, lo que Heidegger llama la <<conversión>> no es un nuevo giro en el movimiento de la reflexión trascendental sino la liberación y realización de esta tarea. Pero, la propia exposición del problema del ser está formulada todavía con los medios de la filosofía trascendental. Sin embargo la renovación a este problema, que Heidegger convierte en su objetivo, significa que en medio del <<positivismo>>, la fenomenología Heidegger orienta su crítica contra el idealismo especulativo a través de la crítica de Husserl. En su hermenéutica de la facticidad sobrepasa el concepto de espíritu y el campo temático de la conciencia trascendental.

En todo caso, como es el de Dilthey, por mucho que éste se esforzara por apegarse a la idea cartesiana de ciencia, a una objetividad de la ciencia tal como la entendía; como objetividad de resultados, tiene un origen distinto. Por eso pudo superar el planteamiento que él mismo había elegido y que consistía en justificar epistemológicamente la peculiaridad metodológica de las ciencias del espíritu.

Frente a tal horizonte, Heidegger, en su análisis del mundo vital y de la fundación anónima de sentido (que constituyó el suelo de toda experiencia), proporcionó al problema de la objetividad en las ciencias del espíritu un nuevo contexto. Tanto las ciencias del espíritu como las de la naturaleza deberán derivarse del rendimiento de la intencionalidad de la vida universal, por lo tanto de una historicidad absoluta. Esta es la única forma de comprender en la que la autorreflexión de la filosofía se hace justicia a sí misma.

A la luz de la resucitada pregunta por el ser, Heidegger está en condiciones de dar a todo esto un giro nuevo y radical. Que ya expusimos al situar el comprender en otro nivel y considerarlo como posibilidad en tanto el modo original del -estar ahí-, El comprender es acá, capacitación, un saber en tanto poder de posibilitar su ser.

Por ello, Gadamer, en el apartado que dedica a Heidegger en Verdad y método, considera que: sobre el trasfondo de este análisis existencial del estar ahí, el ámbito de problemas de la hermenéutica espiritual -científica se presenta de pronto con tonos muy distintos, en cuanto que Heidegger resucita el tema del ser y rebasa con ello a toda la metafísica anterior, gana frente a las aporías 
del historicismo una posición fundamentalmente nueva. El concepto de la comprensión no es ya un asunto de método o de fundamentación: Comprender es para él, el carácter óptico original de la vida humana misma, la reflexión ontológica radical de Heidegger intenta cumplir la tarea de ilustrar la estructura fundamental de la vida misma, esta estructura del estar ahí mediante una <<analítica trascendental del estar ahís>. Descubre así el carácter de proyecto que reviste toda comprensión y piensa ésta misma como el movimiento de la trascendencia, del ascenso por encima de lo que es ${ }^{63}$.

Esto representa una exigencia para la hermenéutica tradicional. La que había estrechado de una manera inadecuada el horizonte de problemas al que pertenece la comprensión. Parece muy distinto el comprender del saber práctico, del orientado cognitivamente en el ejercicio de la ciencia. Por supuesto que si se mira atentamente aparecen rasgos comunes, el que <<comprender > un texto no solo se proyecte a sí mismo, comprendiendo, por referencia a un sentidoen el esfuerzo de comprender -, sino que la comprensión lograda representa un nuevo estadio de libertad espiritual. Implica la posibilidad de interpretar, detectar relaciones, extraer conclusiones en todas las direcciones, que es lo que constituye el <<desenvolverse con conocimiento >> dentro del terreno de la comprensión ${ }^{64}$.

Para Gadamer, la verdad es: que en último extremo toda comprensión es un comprenderse (...) de manera que finalmente se llega a comprender lo oculto. Pero esto significa que uno se entiende con ello (...) el que comprende se proyecta así mismo hacia posibilidades de sí mismo. La ampliación que Heidegger emprende, será particularmente fecunda para el problema de la hermenéutica (...) Pues ahora se hace visible la estructura de la comprensión histórica en toda su fundamentación ontológica, sobre la base de la futuridad existencial del estar ahí humano. Por tanto, el aporte Heidegger, es lo liberado en su análisis: la pre -estructura de la comprensión desde el punto de vista ontológico ${ }^{65}$.

Para Heidegger, la estructura del estar ahí se configura del carácter de estar arrojado a un mundo, mundo articulado por tradiciones y costumbres, en el que el Dasein se instala, articula y está en el mundo. Éste se constituye en gozne y apoyo desde el que se ocupa de su posibilidad. Misma que es futurización. Es decir posibilidad de ser desde su estar "en". Allí se ocupa de su vida, preocupándose, lanzado al futuro como modo de poder ser, que es prever- proveer desde lo recibido en el mundo donde es arrojado e instalado.

Hemos seguido el hilo del análisis que Gadamer realiza del aporte de Heidegger y nos hemos encontrado con ese ser fáctico que, instalado en ese -hoy-, prevé su futuro, su mañana de cada segundo hoy, se lanza hacia lo posible como apropiación de posibilidades para poder ser. Ese preocuparse desata el -poder

63. Para seguir con más detalle, el hilo de todo este análisis que exponemos en estos párrafos, ver : Cfr. GADAMER, G, H. 1993. P.326

64. Ibídem.

65. En estos párrafos, hemos seguido el análisis que Gadamer realiza sobre Heidegger en Verdad y método , en este caso concreto ver P. 331. 
ser- como modo de ser. Un proyectarse desde su estar arrojado, que es la cotidianidad de su modo de estar. En el que lo que hay entre su nacimiento hasta su muerte, es un pre-ocuparse.

Por lo que la estructura del estar allí es un -ser- poder -ser, desde un estar arrojado en un mundo que es sido. Asido al pasado desde el hoy, proyecta su futuro de poder ser. Por ello le compete de suyo el preguntarse por lo que hay. Es pues un radical volverse a lo que hay. A su -sí mismo-, para lanzar su proyecto, desde lo que hay. El Dasein pertenece a un mundo a una tradición en temporalidad, en finitud. Estar allí significa la realización de su propio ser, estar ahí realizándose.

“En consecuencia , y porque el conocimiento histórico recibe su legitimación de la pre-estructura del estar ahí, nadie querrá atacar los criterios inmanentes de lo que quiere decir conocimiento(...) Para Heidegger el conocimiento histórico es y sigue siendo una adecuación a la cosa, una mensuratio ad rem. La cosa es aquí algo cuyo modo de ser es el estar ahí. No un dato, un factum brutum"66.

Con ello, dice Gadamer, queda liberada la hermenéutica de las inhibiciones ontológicas del concepto científico de la verdad y por tanto ya puede hacer justicia a la historicidad de la comprensión, que se planteaba como una dificultad epistemológica.

De modo que queda instalado el problema de la hermenéutica en el carril de una ontología que pone al descubierto la tarea como un mostrar que cualquiera que sea la tarea y comportamiento humano de "cara a sí mismo tropieza y se enfrenta a la vista con la facticidad de su ser. He aquí pues, en oposición a las investigaciones de la constitución trascendental de la fenomenología husserliana, el punto crucial de una $<<$ hermenéutica de la facticidad $>>$. Heidegger (...) es plenamente consciente de estar infranqueablemente precedido por aquello que le da la posibilidad incluso de tener un pro-yecto. Pro-yecto que de hecho incluso no podría ser más que pro-yecto finito" ${ }^{67}$.

Es esta hermenéutica de la facticidad, a juicio de Grondin, el punto de partida de Gadamer: “(...), en ella conoció muy pronto los impulsos que condujeron al <<giro>> del Heidegger, que Gadamer conoció a través de la "superación de la subjetividad del pensamiento moderno (...) Una subjetividad que en griego viene a equivaler a lo fundamental. Procedería de la represión de la temporalidad humana. Gadamer dio a conocer en Verdad y método que <<el giro >> de Heidegger significaba únicamente hacer patente tal intención (...) En este sentido Heidegger orienta su crítica contra el idealismo especulativo a través de la crítica a Husserl en su fundamentación de la hermenéutica de la $<<$ facticidad >>. En la cual realiza una superación del concepto de espíritu del idealismo clásico, como del campo temático de la concepción trascendental, purificado por la reducción fenomenológica. En este sentido, la fenomenología

66. GADAMER, H.G.: Verdad y método, P. 327.

67. GADAMER, H.G.: El problema de la conciencia histórica. P. 78. 
hermenéutica de Heidegger y el análisis de la historicidad del estar-ahí se proponía una renovación general del problema del ser, más que una teoría de las ciencias del espíritu o una superación de las aporías de la historicidad"68.

Para Grondin, el camino hacia el lenguaje que continúa Heidegger, luego de Ser y tiempo, es una consecuencia directa de lo que ya se anunciaba en su hermenéutica de la facticidad y no un cambio abrupto. En este sentido acude a la intuición de Gadamer, en quien ve que el preferir apoyarse en la palabra clave de una hermenéutica de la facticidad desarrollada por Heidegger, éste anuncia el descubrimiento de que la subjetividad humana es secundaria, un momento segundo del existir; y de igual forma Gadamer saca ganancia de la vuelta de Heidegger al lenguaje como experiencia originaria y a la verdad del arte, como una manera de superar desde allí el pensamiento instrumental y técnico de la subjetividad.

Para Gadamer, en tales orientaciones existe una continuidad con el Heidegger de los primeros tiempos, el que abandonó el tema de la hermenéutica. Por ello Grondin considera que Gadamer mismo, al mantenerse fiel al tema de la hermenéutica, relacionó el final del camino del pensamiento heideggeriano con su propio comienzo hermenéutico.

Hemos desbrozado un camino, que consideramos, puede conducir a procesos de mejor comprensión del mundo humano. Para abrir así un diálogo, que es el camino de la comprensión al que nos invita Gadamer. Un mundo que necesita comprenderse y para ello el camino es situare en su temporalidad; para, como dice Heidegger, ver lo que está antes y después de "su puntual ahora". En los apartados dedicados a Gadamer abordaremos el asunto de la condición del diálogo: la voluntad d escucha y con Ricoeur, el reconocimiento del otro, como otro yo, frente a mí. 


\section{Bibliografía}

RICOEUR, Paul.: Política, sociedad e historicidad, Ed. Docencia, Buenos Aires, 1986.

KARL-HEINZ y HILLMANN.: Diccionario de sociología, Ed. Herder, Barcelona, 2001.

MACEIRAS FAFIÁN, Manuel.: La experiencia como argumento, Ed. Síntesis, Madrid, 2007.

GÓMEZ HERAS, José M.: La hermenéutica de la vida en Dilthey y la fundamentación de una <<crítica de la razón histórica >>, Universidad de Córdova.

GADAMER, H, G: Verdad y Método, Ed. Sígueme-Salamanca, 1993.

HEIDEGGER Martín: La idea de la filosofía y el problema de la concepción del mundo, Ed. Herder, Barcelona, 2005.

HEIDEGGER, Martín: Ser y Tiempo, 1997. 